\title{
The Role of the Cerebellum in the Pathophysiology of Parkinson's Disease
}

\author{
Mechelle M. Lewis, Shawna Galley, Samantha Johnson, James Stevenson, \\ Xuemei Huang, Martin J. McKeown
}

\begin{abstract}
Parkinson's disease (PD), the most common neurodegenerative movement disorder, has traditionally been considered a "classic" basal ganglia disease, as the most obvious pathology is seen in the dopaminergic cells in the substantia nigra pars compacta. Nevertheless recent discoveries in anatomical connections linking the basal ganglia and the cerebellum have led to a re-examination of the role of the cerebellum in the pathophysiology of PD. This review summarizes the role of the cerebellum in explaining many curious features of PD: the significant variation in disease progression between individuals; why severity of dopaminergic deficit correlates with many features of PD such as bradykinesia, but not tremor; and why PD subjects with a tremor-predominant presentation tend to have a more benign prognosis. It is clear that the cerebellum participates in compensatory mechanisms associated with the disease and must be considered an essential contributor to the overall pathophysiology of PD.
\end{abstract}

RÉSUMÉ: Rôle du cervelet dans la physiopathologie de la Maladie de Parkinson. La Maladie de Parkinson (MP), le trouble du mouvement de nature neurodégénérative le plus fréquent, a traditionnellement été considérée comme une maladie « classique » des noyaux gris centraux, étant donné que la pathologie la plus évidente se retrouve dans les cellules dopaminergiques de la substance noire de la pars compacta. Néanmoins, des découvertes récentes concernant les connections anatomiques liant les noyaux gris centraux et le cervelet ont mené à un nouvel examen du rôle du cervelet dans la physiopathologie de la MP. Cette revue explique de façon résumée plusieurs aspects singuliers de la MP dans lesquels le cervelet joue un rôle : la variation importante dans la progression de la maladie entre les patients ; pourquoi la sévérité du déficit dopaminergique est en corrélation avec plusieurs manifestations de la MP telle la bradykinésie, mais non avec le tremblement; et pourquoi les patients chez qui le tremblement prédomine ont tendance à avoir un meilleur pronostic. Il est certain que le cervelet participe à des mécanismes compensatoires associés à la maladie et sa contribution doit être considérée comme essentielle à la physiopathologie globale de la MP.

Can J Neurol Sci. 2013; 40: 299-306

The key motor symptoms in Parkinson's disease (PD) include tremor at rest, bradykinesia (slowness of movement), rigidity and, later in the disease, gait disorder/postural instability. These clinical features of PD have assumed to be the direct and indirect result of unexplained degeneration of dopaminergic substantia nigra pars compacta (SNpc) cells of the basal ganglia. Given that many of the motor symptoms in PD can be attributed to dopamine cell loss in the SNpc, the classic model of PD has emphasized the role of basal ganglia dysfunction in PD pathology. However, several key features of the disease cannot be explained adequately by basal ganglia dysfunction alone, including the apparent heterogeneity of the disease (i.e., the existence of PD subtypes $)^{1}$, why patients with akinetic-rigiditydominant PD subtype have a worse prognosis than those with a tremor-dominant PD presentation ${ }^{2-7}$, why PD tremor is less reliably responsive to dopaminergic medications compared to the symptoms of bradykinesia and rigidity ${ }^{8,9}$, or why there is no correlation between rest tremor and striatal ${ }^{18} \mathrm{~F}$-fluorodopa uptake in PD patients ${ }^{10}$.

It is likely that other brain structures outside the basal ganglia play a role in the pathophysiology of the disease. The purpose of this review is to summarize the evidence that cerebellar structures and their connections also may contribute significantly to the signs and symptoms of PD.

\section{The Basal Ganglia and Cerebellum}

Superficially, the subcortical systems of the basal ganglia and cerebellum have much in common. Both systems influence cerebral cortical activity via the thalamus, are linked with the cerebral cortex via recurrent circuits $^{11}$, and affect multiple aspects of motor, cognitive, and affective behaviour ${ }^{12,13}$. Whereas the exact way that each system influences motor output has not been fully elucidated ${ }^{14}$, most models of the basal ganglia emphasize the importance of movement selection in the context of reward ${ }^{15}$, and the basal ganglia are most active when a subject must perform an action that is internally guided (e.g. recalled from memory) from many potential candidates of action ${ }^{14,16-18}$. The cerebellum, traditionally associated with pure motor control, now is considered to be essential for the development of

From the Departments of Neurology (MML, XH), Pharmacology (MML, XH), Radiology (XH), Neurosurgery (XH), Kinesiology (XH), Bioengineering (XH), Pennsylvania State University-Milton S. Hershey Medical Center, Hershey PA, USA; Pacific Parkinson's Research Centre (SG, SJ, JS, MJM), Department of Medicine (Neurology) (MJM), Brain Research Centre (MJM), Department of Electrical and Computer Engineering (MJM), University of British Columbia, Vancouver, British Columbia, Canada.

Received November 22, 2011. Final Revisions Submitted December 7, 2012 Correspondence to: Martin J. McKeown, Neurology, Pacific Parkinson's Research Centre, Brain Research Centre, University of British Columbia, M31, Purdy Pavillion, Vancouver, British Columbia, V6T 2B5, Canada. Email: martin.mckeown@ubc.edu. 
"forward models," such as predicting the sensory consequences of motor actions ${ }^{19,20}$. Cerebellar activity is normally associated with externally guided movements where sensorimotor integration is important ${ }^{14,17,18,21}$. In fact, during an active/passive execution of a motor task consisting of flexion and extension of the elbow, $80-90 \%$ of the neocerebellar signal can be attributed to sensory information processing ${ }^{14}$. This distinction of the roles of the basal ganglia and cerebellar circuits in externally and internally guided tasks, however, is not absolute. Indeed, several studies have demonstrated equal activity in the two pathways during these tasks ${ }^{22,23}$. In addition, there is some evidence that basal ganglia structures may be involved in externally guided tasks $^{24}$ and cerebellar regions are more active during internally guided tasks ${ }^{23}$. The role of the two circuits in externally and internally guided tasks also may be impacted by the study paradigm and/or whether movement preparation or execution is examined. Nevertheless, the outputs from the basal ganglia and cerebellum project to neighboring thalamic nuclei (ventroanterior (VA) and ventrolateral (VL), respectively), which also demonstrate differential involvement in externally and internally guided tasks ${ }^{25,26}$. Anatomical studies using transneuronally transported viruses have demonstrated that projections from the basal ganglia and the cerebellum through the thalamus to the cortex constitute multiple 'parallel' channels forming circuits ${ }^{13}$.

There is little known about the pathophysiological changes of the cerebellum in PD. Imaging studies are equivocal, with some reporting decreased cerebellar volume in $\mathrm{PD}^{27}$ and others not $^{28,29}$. Physiologically, Molnar et $\mathrm{al}^{30}$ demonstrated that PD subjects show decreased firing rates in the VA nucleus of the thalamus, the target of basal ganglia output nuclei, but no alterations in firing of cerebellar-associated VL (called Vim/VPLa in their paper) cells. This study in five PD subjects, however, did not detail the type of PD patients whom they studied and no follow-up studies were reported. Importantly, deep brain stimulation surgery targeting the ventralis intermedius (Vim) thalamic nucleus can capture the tremor associated with essential tremor or $\mathrm{PD}^{31}$, suggesting the role of cerebellum in tremorgenesis. Pathologically, classic pathology studies $^{32}$ reported severe cell loss at the substantia nigra of the basal ganglia, but did not report any cell loss in the cerebellum. Similarly, PD subjects have increased $\alpha$-synuclein in the substantia nigra and basal ganglia but not the cerebellum (Devi et al 2008) ${ }^{33}$. Recent studies suggest that the protein synphilin-1 interacts with $\alpha$-synuclein and also is associated with Lewy bodies in sporadic $\mathrm{PD}^{34}$. Over-expression of wild-type or mutant synphilin-1 protein in a transgenic mouse model leads to both deficits in motor learning and performance, and pathological changes in cerebellar regions including ubiquitin-positive inclusions and degeneration of purkinje cells ${ }^{35}$. Furthermore, cerebellar purkinje cell axonal swelling ('torpedoes') is increased significantly in $\mathrm{PD}^{36}$. There are, however, no detailed patholophysiological studies focused on the role of cerebellar changes in PD, particularly those associated with the different aspect of symptoms, subtypes of disease, or its progression.

While previously considered in isolation, recent evidence has demonstrated that the basal ganglia and cerebellum are anatomically connected. Bostan and Strick $^{37}$ describe a disynaptic projection from the cerebellum to the basal ganglia and a reciprocal projection from the basal ganglia to the cerebellum. Hoshi and colleagues ${ }^{38}$, using transneuronal transport of rabies in non-human primates, revealed a disynaptic pathway that links the dentate nucleus (an output stage of the cerebellum) with the putamen (input nuclei of the basal ganglia) and the globus pallidus externa (GPe; output nuclei of the basal ganglia) via the thalamus. Thus, output from the cerebellum influences the striatum, the target of which includes striatal neurons in the indirect pathway of the basal ganglia. Similarly, Bostan et al observed a disynaptic connection linking the subthalamic nucleus and cerebellar cortex via the pontine nuclei ${ }^{37}$. We recently proposed how striato-thalamo-cortical and cerebello-thalamo-cortical circuits and their interconnections may be functionally organized ${ }^{39}$ (Figure). Interestingly, the projections identified by Bostan et al appear to be topographically organized, such that projections from the dentate nucleus to the primary motor and premotor areas originate from its motor domain, whereas projections from the dentate to prefrontal and parietal areas originate from its non-motor domain ${ }^{40}$. Furthermore, markers for dopaminergic transmission, normally most prominent in the basal ganglia, have been demonstrated to be present and altered in the human cerebellum in $\mathrm{PD}^{41}$.

In addition to anatomical studies, electrophysiological studies suggest a close interaction between the cerebellum and basal ganglia structures. Local field potentials between 12 and $25 \mathrm{~Hz}$ ( $\beta$-band) have been observed widely in the cerebellar cortex ${ }^{42}$ and these are synchronous with activity in the cerebral corte $\mathrm{x}^{43}$. $\beta$-band oscillations also have been detected in the basal ganglia ${ }^{44}$, and while these basal ganglia oscillations are exaggerated in the parkinsonian state ${ }^{45-47}$, they still can be observed being dynamically modulated by simple motor tasks in the striatum of normal primates ${ }^{44}$. It is unclear if $\beta$-band oscillations occur in the cerebellum either in PD or in animal models of the disease. Nevertheless, these collective results suggest that coherent oscillations between cortical and subcortical motor structures (including the basal ganglia and cerebellum) assist in binding the activity of spatially distinct regions ${ }^{48}$.

\section{The Cerebellum and Parkinson's Disease Tremor}

Although dopaminergic treatments are capable of improving symptoms of bradykinesia and rigidity, they are less reliable in improving tremor $^{8}$, consistent with the observation that nigrostriatal dopamine deficiency correlates with bradykinesia but not tremor ${ }^{10}$. In animal models of tremor and parkinsonism, lesions of dopaminergic substantia nigra neurons alone do not produce tremor $^{48}$. In the MPTP (1-methyl-4-phenyl 1,2,3,6tetrahydropyridine) toxin model of parkinsonism, the majority of nonhuman primate species examined exhibit an action/postural tremor $^{50}$ rather than the resting tremor typically observed in human PD. Thus, dopamine depletion in basal ganglia nuclei does not fully account for PD-related tremor.

It is important to highlight the differences between postural and resting tremor. The classic resting tremor observed in PD is low frequency $(4-5 \mathrm{~Hz})$, whereas postural tremor is of a higher frequency $(\sim 8-12 \mathrm{~Hz})$. It has been suggested that rest and postural tremor in PD may be mediated by different neuronal pathways ${ }^{51}$. Postural tremor is the hallmark feature of essential 


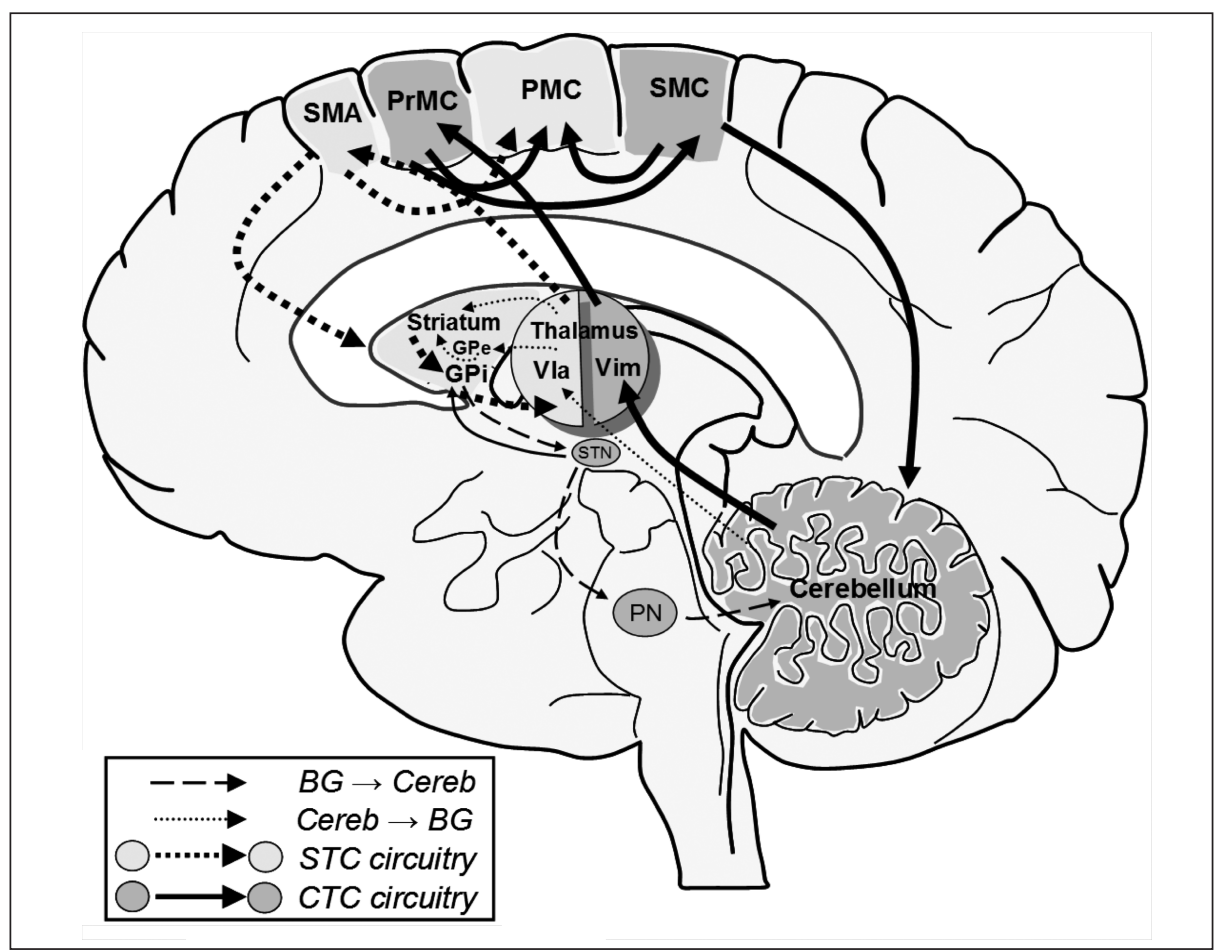

Figure: A conceptual framework for considering STC and CTC circuits. Neuroanatomical evidence indicates that for the STC circuit (light gray structures connected with dashed arrows) the output nucleus of the striatum, the internal segment of the GP, projects to the ventral lateral anterior nucleus of the thalamus, up to the SMA and then PMC, with reciprocal projections back to the striatum. For the CTC circuit (dark gray structures with solid arrows), the cerebellum projects to the ventral intermediate nucleus of the thalamus, up to the premotor cortex and then over to the SMC. The cortex then sends projections back to the cerebellum. In addition, the PrMC and SMC likely send fibers to the final motor endpoint, the PMC. Recent evidence suggests that the basal ganglia ${ }^{37}$ and cerebellum ${ }^{38}$ communicate and/or influence each other's functions at the subcortical level. These connections are indicated using dashed-arrows (basal ganglia to cerebellum) and small-dotted arrows (cerebellum to basal ganglia). BG: basal ganglia, GP: globus pallidus, PMC: primary motor cortex, PN: pontine nuclei, PrMC: lateral premotor cortex, SMA: supplementary motor area, SMC: somatosensory cortex, STN: subthalamic nucleus, Vla: ventrolateral anterior nucleus of the thalamus, Vim: ventral intermediate nucleus of the thalamus (adapted from $^{39}$ ). tremor in humans, although rest tremor also is noted in a large number of these patients ${ }^{52}$. Cerebellar involvement in essential tremor is well accepted ${ }^{30,36}$. Interestingly, when patients with essential tremor have had the disease for a long duration, or have started to develop PD, they also start to have more features of tremor at rest $^{53}$. Our clinical experience and review of the literature indicates that tremor patients only develop the tremordominant type of PD, not the akinetic-rigid type. The cooccurrence of resting tremor in essential tremor patients suggested that there may be a common link regarding to etiology of both types of tremor ${ }^{53}$, and cerebellar dysfunction could well be that common link.

Several lines of evidence suggest the crucial involvement of the cerebellum and/or its circuitry in PD tremor. First, lesion experiments in primates have revealed that tremor can be induced only when there is damage to the nigrostriatal dopaminergic pathway and concomitant damage to the cerebellum or its connections ${ }^{54,55}$, although, interestingly, these lesions result in postural rather than the rest tremor seen in humans. Second, oscillatory bursting at tremor frequencies in the ventralis intermedius of the thalamus in PD patients is consistent with its role in tremor genesis and/or propagation ${ }^{56,57}$, with the Vim principally receiving cerebellar inputs rather than projections from basal ganglia structures ${ }^{58}$. Third, surgical lesions or long-term stimulation of the Vim consistently improves tremor symptoms ${ }^{59-62}$, and the Vim has been established as an effective surgical site for treating PD tremor $^{31,63}$. Notably, Vim surgery does not ameliorate bradykinesia and/or rigidity ${ }^{64}$. Lastly, recent functional imaging network analysis provides evidence that a distinct cerebellothalamo-cortical circuit may mediate tremor in $\mathrm{PD}^{65}$.

Several studies have observed abnormal activity in the cerebellum in relation to $\mathrm{PD}$ tremor. Positron emission tomography (PET) studies have demonstrated that resting activity of rostral, medial, and intermediate cerebellum (vermis and paravermis) is increased in PD tremor ${ }^{66,67}$, and cerebellar hyperactivity of rostral vermis and paravermis is reduced when effective thalamic Vim stimulation arrests tremor. These results suggest that tremor suppression is primarily associated with decreased synaptic activity in the cerebellum ${ }^{68,69}$. Consistent with these findings is the observation that grey matter volume in the right quadrangular lobe and declive of the cerebellum is decreased in PD patients with rest tremor ${ }^{70}$.

Oscillatory activity in the cerebellum itself in patients with rest tremor has been reported ${ }^{71}$. These findings strongly implicate the involvement of altered cerebellum activity in tremor in light of the fact that the P3rkinje cells in lobules IV-VI of the cerebellar cortex (where grey matter decreases are observed) provide input to the arm area of the primary motor cortex (M1). These data are consistent with the notion that the cerebellum may be one part of a circuit that is involved in the propagation and/or transmission of tremor and/or tremor can be a consequence of a complicated interplay between basal ganglia and cerebellar circuits as suggested recently by Helmich et al (2011).

Tremor-dominant PD patients reportedly have a better prognosis since they have less dyskinesias and motor fluctuations in response to levodopa ${ }^{72}$ and less frontal lobe deficits $^{73}$ compared to akinetic-rigid patients (Table 1). The exact reason for the better prognosis in tremor-dominant PD is unknown, although it is possible that the better prognosis observed may be less due to basal ganglia pathology in tremordominant PD patients than that seen in the akinetic rigidity type of PD. This hypothesis has not been tested, however, and further studies are warranted. 
Lewis et al recently investigated the role of tremor in PD by studying functional differences between PD subtypes using $\mathrm{fMRI}^{39}$. Nine tremor-dominant PD, eight akinetic-rigiddominant PD, and 14 control subjects completed a sequential finger tapping task followed by comparison of activity in striatothalamo-cortical and cerebello-thalamo-cortical circuits. Compared to controls, both tremor- and akinetic-rigid-dominant PD subjects displayed overall increased activity in striatothalamo-cortical and cerebello-thalamo-cortical pathways. Interestingly, the comparison of akinetic rigid- and tremordominant PD subjects revealed significant differences in cerebellar circuits, lending further support to the role of cerebellar circuitry in PD and underscoring the involvement of cerebello-thalamo-cortical pathways in tremorgenesis.

\section{Cerebellar activity as a compensatory mechanism in PD}

Motor symptoms in PD only occur after an estimated $50 \%$ of dopaminergic nigral cells and $60-80 \%$ of striatal dopamine levels have been $\operatorname{lost}^{74,75}$. Further, imaging measures of pathological disease progression, such as ${ }^{18} \mathrm{~F}$-dopa PET, do not correlate necessarily with clinical measures of disability, such as the Unified Parkinson's Disease Rating Scale (UPDRS) ${ }^{76}$. The lack of observed motor pathology despite significant cell loss indicates the existence of redundancy and/or compensatory mechanisms that serve to delay the onset of symptoms and preserve an optimal level of motor function ${ }^{77,78}$.

Part of the reason the cerebellum has not heretofore been considered as a primary site for systems-level compensation in $\mathrm{PD}$ is the difficulty in differentiating actual compensatory changes from direct disease-related changes. This requires a rigorous definition of compensation. For the purpose of this paper, we define compensation to mean, "any change, morphological or functional, seen in the damaged brain, that acts to maintain performance of the impaired function."

The cerebellum may be involved in the increased reliance on external visual or auditory cues observed in $\mathrm{PD}^{79-83}$. Likely the most dramatic case of the use of visual cues is that of kinesia paradoxa ${ }^{84}$. In kinesia paradoxa, PD subjects described as "frozen" have anecdotally gained the sudden ability to move in urgent situations. One explanation put forth for this phenomenon is that intact cerebellar pathways may allow patients to bypass the compromised basal ganglia pathway, enabling them to utilize vision to guide their movements ${ }^{84}$. The properties of the stimuli that are effective in helping patients guide their movements (e.g., transverse stripes on the floor) are similar to those of visual signals that are relayed by mossy fibers via the posterior parietal cortex and the pontine nuclei to the cerebellum. The receptive fields of the visual neurons along this pathway tend to be tuned to horizontal gratings in the lower visual field, therefore, a staircase or stripes on the floor may activate the neurons along the visual cortex $\rightarrow$ posterior parietal $\rightarrow$ pontine nuclei $\rightarrow$ mossy fiber $\rightarrow$ cerebellum pathway ${ }^{84,85}$. Thus, the clinical observation that PD patients become increasingly reliant on external visual cues to successfully perform movements represents a compensatory strategy that involves a switch to more visually guided motor networks and likely cerebellar pathways.

Motor urgency, closely related to kinesia paradoxica, recently has been shown to involve cerebellar circuits. In a study by Ballanger et $\mathrm{al}^{86}$, participants were instructed to stop a rolling ball with a button-controlled electromagnetic catch. They were instructed to stop as many balls as possible when prompted by an auditory cue. Patients demonstrated increased activation of the cerebellum generally, and when comparing the "urgent" externally cued to the externally cued task there was increased activation in the contralateral cerebellum. Interestingly, the speed of movement demonstrated a significant negative covariation with regional cerebral bloodflow (rCBF) in left parasagittal cerebellar hemisphere, with shorter movement time associated with greater activation in the cerebellum. These findings lend further support to the proposition that patients recruit the cerebellum in order to compensate for basal ganglia dysfunction so as to increase movement velocity in urgent contexts.

Lewis et al examined a monozygotic twin pair discordant for PD with fMRI while they performed both externally and internally guided finger tapping sequences ${ }^{87}$. Single photon emission computed tomography (SPECT) with [I-123](-)-2- $\beta$ carboxymethoxy-3- $\beta$-(4-iodophenyl) tropane $(\beta-\mathrm{CIT})$ was used to confirm disease status, which revealed severe loss of transporter binding in the PD twin, whereas the non PD twin was normal. No significant differences were found between the twins in the striato-thalamo-cortical pathway during the externally

Table: Comparison of different subtypes of Parkinson's disease

\begin{tabular}{l|l|l}
\hline & Parkinson's disease Clinical subtype \\
\hline Clinical features & PD & PD $_{\text {AR }}$ \\
\hline $\begin{array}{l}\text { Progression of motor symptoms } \\
\text { Freezing gait }\end{array}$ & Slower/not worsening & Faster \\
\hline Inheritance & More & Higher familial incidence of other cases of PD \\
\hline PET Scan & Higher prevalence of Essential Tremor & $\begin{array}{l}\text { Correlates with nigrostriatal dopaminergic } \\
\text { deficiency }\end{array}$ \\
\hline SPECT & $\begin{array}{l}\text { Does not correlate with nigrostriatal } \\
\text { dopaminergic deficit }\end{array}$ & \\
\hline Pathology & $\begin{array}{l}\text { Less neuronal loss in locus coeruleus, } \\
\text { medial and lateral parts of SN }\end{array}$ & $\begin{array}{l}\text { Higher neuronal losses in locus coeruleus, medial } \\
\text { and lateral parts of SN }\end{array}$ \\
\hline
\end{tabular}

$\mathrm{DLPFC}=$ dorsolateral prefrontal cortex $\mathrm{PET}=$ positron emission topography; SPECT= single-photon emission computed tomography; $\mathrm{PD}_{\mathrm{T}}=$ tremor-dominant Parkinson's patients; $\mathrm{PD}_{\mathrm{AR}}=$ akinetic and rigid-dominant Parkinson's patients; $\mathrm{SN}=$ substantia nigra 
guided task. In contrast, the PD twin demonstrated increased activity in the cerebello-thalamo-cortical circuit relative to the non-PD twin during the externally guided task. This cerebellothalamo-cortical hyperactivity was relatively normalized by levodopa. During the internally guided task, the PD twin demonstrated decreased activation compared to the non-PD twin in both circuits. L-dopa medication normalized the hypoactivation in the contralateral striato-thalamo-cortical pathway, but appeared to over-correct activation in the ipsilateral striato-thalamo-cortical and bilateral cerebello-thalamo-cortical circuits. Similarly, an earlier study by Cerasa et al investigated the neurofunctional basis of externally and internally guided movements in PD patients and controls, with an overall signal increase in patients compared to controls in the cerebellum, putamen, supplementary motor area (SMA), and thalamus during their externally guided $\operatorname{task}^{22}$. Unlike Lewis et $\mathrm{al}^{87}$, however, the authors observed increased recruitment of the cerebello-thalamo-cortical circuit in patients during the internally guided task. This difference may be explained by the use of a timing task by Cerasa et al, which likely engages the cerebellum more than the sequencing task used in Lewis et $\mathrm{al}^{87}$. It is important to note, however, that the role of the striatothalamo-cortical and cerebello-thalamo-cortical circuits in externally and internally guided tasks is influenced by many factors (e.g., study paradigm, aspect of movement examined, measurement method, etc.) and thus the distinction is not absolute (see, for example Cerasa et $\mathrm{al}^{22}$ and Gowen and Miall ${ }^{23}$ )

Increased cerebello-thalamo-cortical activity also may be involved in the progression of PD. Sen et al recently gathered fMRI scans two years apart from five PD and five control subjects while they performed both externally and internally guided tasks ${ }^{88}$. All PD subjects had unilateral symptoms at baseline that developed into bilateral symptoms at the follow-up time point. Importantly, significant differences over time between PD patients and controls were observed in the cerebello-thalamo-cortical during the internally guided task. In addition, patients demonstrated more recruitment in the cerebello-thalamo-cortical circuit when the internally guided task was performed by the hand that transitioned from unaffected to symptomatic. This finding suggests that the emergence of symptoms on the less affected side may reflect a breakdown of a previously relatively more intact striato-thalamo-cortical pathway, which may lead to compensatory recruitment of the cerebello-thalamo-cortical circuit and permit successful performance on an internally guided task. Conversely, the increased cerebello-thalamo-cortical activity may represent increased pathological processes in PD progression, although this study could not delineate definitively between compensatory and/or pathological processes (see next section 'Cerebellar Activity and Forward Models in PD').

$\mathrm{Yu}$ and colleagues ${ }^{89}$ used BOLD contrast fMRI to examine patients and controls while they performed automatic and cognitively-controlled thumb pressing movements ${ }^{89}$. In both conditions, patients demonstrated an augmented BOLD signal increase in the cerebellum and M1 relative to controls, whereas they displayed less activation in putamen and SMA. Further, PD subjects showed a significant negative correlation between activation in the ipsilateral cerebellum and contralateral putamen. Although this may be a compensatory increase in cerebellum activity as a result of putaminal deficiency as suggested by the authors, it is hard to distinguish an epiphenomenon from true compensatory activity unless the motor performance correlates with the hyperactivity.

One possible method to assess compensatory changes is to require patients to perform tasks that are challenging for them or tasks that increase in difficulty. This approach relies on the assumption that disease-related changes are relatively static across variations in task difficulty, whereas compensatory mechanisms, which are recruited to maintain or improve performance, should show a monotonic relationship with the difficulty of the task. In the following discussion, we present data that are consistent with this assumption, although we recognize that rigorous definitions of how to differentiate between disease and compensatory changes are an ongoing source of debate.

Parkinson's disease patients increasingly rely on cerebellar structures when the motor demands of the task increase in level of difficulty. Palmer et al recently examined motor reserve as a compensatory mechanism in $\mathrm{PD}^{90}$. Active motor reserve, a concept drawn from cognitive reserve ${ }^{91}$, is defined as increased recruitment of a task-related network that monotonically increases with task difficulty in healthy participants in order to maintain performance. This is distinguished from novel area recruitment (NAR), whereby novel areas or networks are recruited as additional resources to maintain a near-normal level of performance as task difficulty increases. In this study, PD participants and healthy controls were asked to provide sinusoidal force production at three different speeds $(0.25,0.5$, and $0.75 \mathrm{~Hz}$ ) while in the magnetic resonance scanner. Multiple linear regression analyses revealed that activity linearly increased with movement speed in regions of the basal ganglia in healthy controls, most notably in bilateral putamen and thalamus. Off medication, PD patients maximally recruited this same network at lower speeds, suggesting that PD subjects tap into motor reserve earlier to maintain task performance. To perform the task at higher speeds, patients needed to recruit new areas by shifting to a compensatory network that included the cerebello-thalamo-cortical loop. These observations are likely to reflect compensatory changes since patients maximally recruited the normal motor network during the lowest level of task difficulty, but then engaged areas of the cerebello-thalamocortical network as the task became more challenging. Supportive of this hypothesis is the fact that the compensatory activity in the cerebello-thalamo-cortical network increased monotonically as task difficulty increased.

\section{Compensatory changes in functional and effective connectivity}

Rather than examining discrete loci for hyper/hypo activation, a number of studies have examined changes in connectivity between brain regions as a purported compensatory mechanism. Studies alluding to "connectivity" can refer to functional connectivity, the temporal correlation between spatially distinct neurophysiological events ${ }^{92}$, or effective connectivity, a connectivity pattern that reveals the strength and directionality of information flow ${ }^{93}$. A recent study compared the functional connectivity in the motor network between healthy controls and PD patients off and on levodopa during the resting 
state $^{94}$. Patients off medication demonstrated decreased connectivity in the SMA, left DLPFC, and left putamen, and increased connectivity in the left cerebellum, left M1, and left parietal cortex. Administration of levodopa relatively normalized these connectivity patterns in patients. These results are consistent with the regional hypo- and hyperactivation patterns seen in the prior imaging studies discussed above.

A study that jointly examined amplitude and connectivity changes found distinct changes in connectivity between PD subjects and controls ${ }^{95}$. Most notably, PD subjects alone demonstrated increased interhemispheric connectivity within the cerebello-thalamo-cortical pathway. Only amplitude changes, however, were modulated by task difficulty. These results indicate that connectivity changes may represent more permanent plastic changes that are relatively task-independent.

\section{Cerebellar activity and forward models in PD}

Recently, Stevenson et al investigated the response of PD subjects to less informative and extraneous visual stimuli during motor performance ${ }^{96}$. Subjects performed large-amplitude arm movements as part of a visually guided tracking task where the position of the tracked target became progressively ambiguous as it 'jittered' about a desired trajectory at different amplitudes. Healthy human subjects demonstrated the ability to de-weight ambiguous visual feedback during motor tasks in order to preserve motor performance ${ }^{97-100}$. However, the motor performance of PD subjects off medication significantly deteriorated with increasing ambiguous visual input. This may be a result of cerebellar dysfunction in $\mathrm{PD}$, as evidence indicates cerebellar forward models are used to mitigate the effect of sensory uncertainty on motor performance ${ }^{101,102}$. Thus, while the use of visual feedback may allow for improvements in motor performance in PD, parkinsonian motor performance is particularly sensitive to visual feedback that is uncertain and extraneous, suggesting the functional effect of cerebellar compensation in PD may be task dependent.

\section{CONCLUding Remarks}

Many clinical features of PD cannot be attributed exclusively to basal ganglia dysfunction. The work described in this review provides evidence for the role of the cerebellum in PD symptomology and compensation for the damaged and dysfunctional striato-thalamo-cortical pathway. Altered cerebellar connectivity, as well as compensatory activity, however, may come with a price. In demonstrating the key position the cerebellum has in providing compensation for basal ganglia dysfunction through its reciprocal connections with the basal ganglia, Hoshi and colleagues queried, "when basal ganglia activity is abnormal, is cerebellar input part of the problem or part of the solution?"38 In addition to the importance of the cerebellum in providing redundancy and compensatory activity in PD, it also has been implicated in tremor generation, which may confound our understanding of the role of the cerebellum in PD. Patients diagnosed with the tremor-dominant subtype have a better prognosis and typically slower disease progression than patients with akinetic-rigid dominant PD. A smaller role for compensatory cerebellar activity in tremordominant PD patients may be one explanation for the slower progression and lower occurrence of dyskinesia observed in this
PD subtype. Several studies have demonstrated increased recruitment of cerebello-thalamo-cortical circuits in PD, and we have shown a clear difference in this pathway between tremorand akinetic-rigid-dominant PD subtypes. Moreover, cerebellothalamo-cortical circuits appear to be involved in PD progression, as there is increased activation in the cerebellothalamo-cortical pathway as subjects transition from unilateral to bilateral symptoms. Further studies have demonstrated changes in functional connectivity in the cerebello-thalamo-cortical pathways in PD. Collectively, these results affirm that the cerebellum should be increasingly recognized as being essential for the pathophysiology of PD.

\section{ACKNOWLEDGMENTS}

The authors thank all those who participated in the study and support of the UNC and UBC MRI centers. This work was supported, in part, by NIH grants AG21491 (XH), NS060722 (XH and MML), the UNC GCRC (RR00046), a Collaborative Health Research Grant (CHRP, MJM), and a Canadian Institute of Health Research (CIHR) Grant MJM).

\section{REFERENCES}

1. Jankovic J, McDermott M, Carter J, et al. Variable expression of Parkinson's disease: a base-line analysis of the DATATOP cohort. The Parkinson Study Group. Neurology. 1990;40: 1529-34.

2. Hoehn MM, Yahr MD. Parkinsonism - onset progression and mortality. Neurology. 1967;17(5):427-42.

3. Guillard A, Chastang C. Long-term prognostic factors in Parkinson's disease. Rev Neurol. 1978;134(5):341-54.

4. Guillard A, Chastang C, Fenelon G. Long-term study of 416 cases of Parkinson disease. Prognostic factors and therapeutic implications. Rev Neurol. 1986;142(3):207-14.

5. Goetz CG, Tanner CM, Stebbins GT, Buchman AS. Risk factors for progression in Parkinson's disease. Neurology. 1988;38(12): 1841-4.

6. Jankovic J, Kapadia AS. Functional decline in Parkinson disease. Arch Neurol. 2001;58(10):1611-15.

7. Marras C, Rochon P, Lang AE. Predicting motor decline and disability in Parkinson disease: a systematic review. Arch Neurol. 2002;59(11):1724-8.

8. Koller WC, Hubble JP. Levodopa therapy in Parkinson's disease. Neurology. 1990;40(Suppl 3):40-7.

9. Marjama-Lyons J, Koller W. Tremor-predominant Parkinson's disease. Approaches to treatment. Drugs Aging. 2000;16(4): 273-8.

10. Vingerhoets FJ, Schulzer M, Calne DB, Snow BJ. Which clinical sign of Parkinson's disease best reflects the nigrostriatal lesion? Ann Neurol. 1997;41(1):58-64.

11. Afifi AK, Bergman RA. Functional Neuroanatomy: text and atlas. New York: McGraw-Hill; 1998.

12. Alexander GE, DeLong MR, Strick PL. Parallel organization of functionally segregated circuits linking basal ganglia and cortex. Annu Rev Neurosci. 1986;9(1):357-81.

13. Middleton FA, Strick PL. Basal ganglia and cerebellar loops: motor and cognitive circuits. Brain Res Rev. 2000;31:236-50.

14. Jueptner M, Weiller C. A review of differences between basal ganglia and cerebellar control of movements as revealed by functional imaging studies. Brain. 1998;121(Pt 8):1437-49.

15. Bar-Gad I, Bergman H. Stepping out of the box: information processing in the neural networks of the basal ganglia. Curr Opin Neurobiol. 2001;11(6):689-95.

16. Mushiake H, Strick PL. Pallidal neuron activity during sequential arm movements. J Neurophysiol. 1995;74(6):2754-8.

17. van Donkelaar P, Stein JF, Passingham RE, Miall RC. Neuronal activity in the primate motor thalamus during visually triggered and internally generated limb movements. J Cereb Blood Flow Metab. 1999;16:23-33. 
18. van Donkelaar P, Stein JF, Passingham RE, Miall RC. Temporary inactivation in the primate motor thalamus during visually triggered and internally generated limb movements. J Neurophysiol. 2000;83(5):2780-90.

19. Blakemore SJ, Frith CD, Wolpert DM. The cerebellum is involved in predicting the sensory consequences of action. Neuroreport. 2001;12(9): 1879-84.

20. Miall RC, Jenkinson EW. Functional imaging of changes in cerebellar activity related to learning during a novel eye-hand tracking task. Exp Brain Res. 2005;166(2):170-83.

21. Jueptner J, Jueptner M, Jenkins IH, Brooks DJ, Frackowiak RSJ, Passingham RE. The sensory guidance of movement: a comparison of the cerebellum and basal ganglia. Exp Brain Res. 1996;112(3):462-74

22. Cerasa A, Hagberg GE, Peppe A, et al. Functional changes in the activity of cerebellum and frontostriatal regions during externally and internally timed movement in Parkinson's disease. Brain Res Bull. 2006 Dec;71(1-3):259-69.

23. Gowen E, Miall R. Differentiation between external and internal cuing: An fMRI study comparing tracing with drawing. Neuroimage. 2007;36(2):396-410.

24. Purzner J, Paradiso GO, Cunic D, et al. Involvement of the basal ganglia and cerebellar motor pathways in the preparation of selfinitiated and externally triggered movements in humans. J Neurosci. 2007;27(22):6029.

25. MacMillan ML, Dostrovsky JO, Lozano AM, Hutchison WD. Involvement of human thalamic neurons in internally and externally generated movements. Am Physiol Soc; 2004. p. 1085-90.

26. Vaillancourt DE, Thulborn KR, Corcos DM. Neural basis for the processes that underlie visually guided and internally guided force control in humans. J Neurophsyiol. 2003;90(5):3330-40.

27. Borghammer P, Østergaard K, Cumming P, et al. A deformationbased morphometry study of patients with early-stage Parkinson's disease. Eur J Neurol. 2010;17(2):314-20.

28. Linder J, Birgander R, Olsson I, et al. Degenerative changes were common in brain magnetic resonance imaging in patients with newly diagnosed Parkinson's disease in a population-based cohort. J Neurol. 2009;256(10):1671-80.

29. Messina D, Cerasa A, Condino F, et al. Patterns of brain atrophy in Parkinson's disease, progressive supranuclear palsy and multiple system atrophy. Parkinsonism Relat Disord. 2011;17(3):172-6.

30. Molnar GF, Pilliar A, Lozano AM, Dostrovsky JO. Differences in neuronal firing rates in pallidal and cerebellar receiving areas of thalamus in patients with Parkinson's disease, essential tremor, and pain. J Neurophysiol. 2005;93(6):3094-101.

31. Narabayashi H, Maeda T, Yokochi F. Long-term follow-up study of nucleus ventralis intermedius and ventrolateralis thalamotomy using a microelectrode technique in parkinsonism. App Neurophysiol. 1987;50(1-6):330-7.

32. Jellinger KA. Pathology of Parkinson's disease. Mol Chem Neuropathol. 1991;14(3):153-97.

33. Devi L, Raghavendran V, Prabhu BM, Avadhani NG, Anawdatheerthavarada HK. Mitochondrial import and accumulation of alpha-synuclein impair complex I in human dopaminergic neuronal cultures and Parkinson disease brain. J Biol Chem. 2008 Apr 4;283(14):9089-100.

34. Engelender S, Kaminsky Z, Guo X, et al. Synphilin-1 associates with alpha-synuclein and promotes the formation of cytosolic inclusions. Nat Genet. 1999;22(1):110-14.

35. Nuber S, Franck T, Wolburg H, et al. Transgenic overexpression of the alpha-synuclein interacting protein synphilin-1 leads to behavioral and neuropathological alterations in mice. Neurogenetics. 2010;11(1):107-20.

36. Louis ED, Yi H, Erickson-Davis C, Vonsattel JPG, Faust PL. Structural study of Purkinje cell axonal torpedoes in essential tremor. Neurosci Lett. 2009;450(3):287-91.

37. Bostan AC, Dum RP, Strick PL. The basal ganglia communicate with the cerebellum. P Natl Acad Sci USA. 2010;107(18): 8452-6.

38. Hoshi E, Tremblay L, Feger J, Carras PL, Strick PL. The cerebellum communicates with the basal ganglia. Nat Neurosci. $2005 ; 8: 1491-3$
39. Lewis MM, Du G, Sen S, et al. Differential involvement of striatoand cerebello-thalamo-cortical pathways in tremor-and akinetic/rigid-predominant Parkinson's disease. Neurosci. 2011 Mar 17;177:230-9.

40. Bostan AC, Strick PL. The cerebellum and basal ganglia are interconnected. Neuropsychol Rev. 2010;20(3):261-70.

41. Hurley MJ, Mash DC, Jenner P. Markers for dopaminergic neurotransmission in the cerebellum in normal individuals and patients with Parkinson's disease examined by RT-PCR. Eur J Neurosci.18(9):2668-72.

42. Courtemanche R, Pellerin J-P, Lamarre Y. Local field potential oscillations in primate cerebellar cortex: modulation during active and passive expectancy. J Neurophysiol. 2002;88(2): 771-82.

43. Courtemanche R, Lamarre Y. Local field potential oscillations in primate cerebellar cortex: synchronization with cerebral cortex during active and passive expectancy. J Neurophysiol. 2005;93 (4):2039-52.

44. Courtemanche R, Fujii N, Graybiel AM. Synchronous, focally modulated beta-band oscillations characterize local field potential activity in the striatum of awake behaving monkeys. J Neurosci. 2003 Dec 17;23(37):11741-52.

45. Brown P, Oliviero A, Mazzone P, Insola A, Tonali P, Di Lazzaro V. Dopamine dependency of oscillations between subthalamic nucleus and pallidum in Parkinson's disease. J Neurosci. 2001; 21(3): 1033

46. Raz A, Frechter-Mazar V, Feingold A, Abeles M, Vaadia E, Bergman H. Activity of pallidal and striatal tonically active neurons is correlated in MPTP-treated monkeys but not in normal monkeys. J Neurosci. 2001;21(3):RC128.

47. Williams D, Tijssen M, Van Bruggen G, et al. Dopamine-dependent changes in the functional connectivity between basal ganglia and cerebral cortex in humans. Brain. 2002 Jul;125(Pt 7):1558-69.

48. Schnitzler A, Gross J. Normal and pathological oscillatory communication in the brain. Nat Rev Neurosci. 2005;6:1-13.

49. Poirier LJ, Pechadre JC, Larochelle L, Dankova J, Boucher R. Stereotaxic lesions and movement disorders in monkeys. Adv Neurol. 1975; 10:5-22.

50. Burns RS, Chiueh CC, Markey SP, Ebert MH, Jacobowitz DM, Kopin IJ. A primate model of Parkinsonism: selective destruction of dopaminergic neurons in the pars compacta of the substantia nigra by N-methyl-4-phenyl-1, 2, 3, 6tetrahydropyridine. P Natl Acad Sci USA. 1983;80(14):4546-50.

51. Ni Z, Pinto AD, Lang AE, Chen R. Involvement of the cerebellothalamocortical pathway in Parkinson disease. Ann Neurol. 2010;68(6):816-24.

52. Cohen O, Pullman S, Jurewicz E, Watner D, Louis ED. Rest tremor in patients with essential tremor: prevalence, clinical correlates, and electrophysiologic characteristics. Arch Neurol. 2003;60 (3): 405 .

53. Minen MT, Louis ED. Emergence of Parkinson's disease in essential tremor: a study of the clinical correlates in 53 patients. Mov Dis. 2008;23(11): 1602-5.

54. Pechadre JC, Larochelle L, Poirier LJ. Parkinsonian akinesia, rigidity and tremor in the monkey. Histopathological and neuropharmacological study. J Neurol Sci. 1976;28(2):147-57.

55. Marsden CD, Obeso JA. The functions of the basal ganglia and the paradox of stereotaxic surgery in Parkinson's disease. Brain. 1994;117:877-97.

56. Hua S, Reich SG, Zirh AT, Perry V, Dougherty PM, Lenz FA. The role of the thalamus and basal ganglia in parkinsonian tremor. Mov Dis. 1998;13 Suppl 3:40-2.

57. Lenz FA, Kwan HC, Martin RL, Tasker RR, Dostrovsky JO, Lenz YE. Single unit analysis of the human ventral thalamic nuclear group. Tremor-related activity in functionally identified cells. Brain. 1994;117(Pt 3):531-43.

58. Inase M, Tanji J. Thalamic distribution of projection neurons to the primary motor cortex relative to afferent terminal fields from the globus pallidus in the macaque monkey. J Comp Neurol. 1995; 353(3):415-26.

59. Benabid AL, Pollak P, Gervason C, et al. Long-term suppression of tremor by chronic stimulation of the ventral intermediate thalamic nucleus. Lancet. 1991;337(8738):403-6. 
60. Caparros-Lefebvre D, Blond S, Vermersch P, Pecheux N, Guieu JD, Petit H. Chronic thalamic stimulation improves tremor and levodopa induced dyskinesias in Parkinson's disease. J Neurol Neurosurg Psychiatry. 1993;56(3):268-73.

61. Koller W, Pahwa R, Busenbark K, et al. High-frequency unilateral thalamic stimulation in the treatment of essential and parkinsonian tremor. Ann Neurol. 1997;42(3):292-9.

62. Limousin-Dowsey P, Pollak P, Van Blercom N, Krack P, Benazzouz A, Benabid A. Thalamic, subthalamic nucleus and internal pallidum stimulation in Parkinson's disease. J Neurol. 1999;246 Suppl 2:II42-5

63. Lenz FA, Normand SL, Kwan HC, et al. Statistical prediction of the optimal site for thalamotomy in parkinsonian tremor. Mov Dis. 1995;10(3):318-28.

64. Jankovic J, Cardoso F, Grossman RG, Hamilton WJ. Outcome after stereotactic thalamotomy for parkinsonian, essential, and other types of tremor. Neurosurgery. 1995;37(4):680-7

65. Mure H, Hirano S, Tang CC, et al. Parkinson's disease tremorrelated metabolic network: characterization, progression, and treatment effects. Neuroimage. 2011;54(2):1244-53.

66. Duffau H, Tzourio N, Caparros-Lefebvre D, Parker F, Mazoyer B. Tremor and voluntary repetitive movement in Parkinson's disease: comparison before and after L-dopa with positron emission tomography. Exp Brain Res. 1996;107(3):453-62.

67. Antonini A, Moeller JR, Nakamura T, Spetsieris P, Dhawan V, Eidelberg D. The metabolic anatomy of tremor in Parkinson's disease. Neurology. 1998;51(3):803-10.

68. Deiber MP, Pollak P, Passingham R, et al. Thalamic stimulation and suppression of parkinsonian tremor. Evidence of a cerebellar deactivation using positron emission tomography. Brain. 1993; 116(Pt 1):267-79.

69. Fukuda M, Barnes A, Simon ES, et al. Thalamic stimulation for parkinsonian tremor: correlation between regional cerebral blood flow and physiological tremor characteristics. Neuroimage. 2004 Feb;21(2):608-15.

70. Benninger DH, Thees S, Kollias SS, Bassetti CL, Waldvogel D. Morphological differences in Parkinson's disease with and without rest tremor. J Neurol. 2009;256(2):256-63.

71. Timmermann L, Gross J, Dirks M, Volkmann J, Freund HJ, Schnitzler A. The cerebral oscillatory network of parkinsonian resting tremor. Brain. 2003;126(Pt 1):199-212.

72. Caraceni T, Scigliano G, Musicco M. The occurrence of motor fluctuations in parkinsonian patients treated long term with levodopa. role of early treatment and disease progression. Neurology. 1991 Mar;41(3):380-4.

73. Mayeux R, Stern Y, Rosen J, Frank Benson D. Is "subcortical dementia" a recognizable clinical entity? Ann Neurol. 1983;14 (3):278-83

74. Fearnley JM, Lees AJ. Ageing and Parkinson's disease: substantia nigra regional selectivity. Brain. 1991;114(Pt 5):2283-301.

75. Lee CS, Samii A, Sossi V, et al. In vivo positron emission tomographic evidence for compensatory changes in presynaptic dopaminergic nerve terminals in Parkinson's disease. Ann Neurol. 2000;47:493-503.

76. Morrish PK, Sawle GV, Brooks DJ. An [18F]dopa-PET and clinical study of the rate of progression in Parkinson's disease. Brain. 1996;119(Pt 2):585-91.

77. Zigmond MJ, Abercrombie ED, Berger TW, Grace AA, Stricker EM. Compensations after lesions of central dopaminergic neurons: some clinical and basic implications. Trends Neurosci. 1990;13(7):290-6

78. Bezard E, Crossman AR, Gross CE, Brotchie JM. Structures outside the basal ganglia may compensate for dopamine loss in the presymptomatic stages of Parkinson's disease. FASEB J. 2001;15(6):1092-4.

79. Chuma T, Faruque Reza M, Ikoma K, Mano Y. Motor learning of hands with auditory cue in patients with Parkinson's disease. J Neural Transm. 2006;113(2):175-85

80. Jahanshahi M, Jenkins I, Brown R, Marsden C, Passingham R, Brooks D. Self-initiated versus externally triggered movements: I. An investigation using measurement of regional cerebral blood flow with PET and movement-related potentials in normal and Parkinson's disease subjects. Brain. 1995;118(4):913.
81. Georgiou N, Iansek R, Bradshaw JL, Phillips JG, Mattingley JB, Bradshaw JA. An evaluation of the role of internal cues in the pathogenesis of parkinsonian hypokinesia. Brain. 1993;116(Pt 6): $1575-87$

82. Lewis GN, Byblow WD, Walt SE. Stride length regulation in Parkinson's disease: the use of extrinsic, visual cues. Brain. 2000;123(Pt 10):2077-90.

83. Oliveira RM, Gurd JM, Nixon P, Marshall JC, Passingham RE. Micrographia in Parkinson's disease: the effect of providing external cues. J Neurol Neurosurg Psychiatry. 1997 Oct;63(4): 429-33.

84. Glickstein M, Stein J. Paradoxical movement in Parkinson's disease. Trends Neurosci. 1991;14(11):480-2.

85. Suzuki DA, Keller EL. Visual signals in the dorsolateral pontine nucleus of the alert monkey: their relationship to smooth-pursuit eye movements. Exp Brain Res. 1984;53(2):473-8

86. Ballanger B, Baraduc P, Broussolle E, Le Bars D, Desmurget M, Thobois S. Motor urgency is mediated by the contralateral cerebellum in Parkinson's disease. J Neurol Neurosurg Psychiatry. 2008 Oct;79(10):1110-16.

87. Lewis M, Slagle C, Smith A, et al. Task specific influences of Parkinson's disease on the striato-thalamo-cortical and cerebello-thalamo-cortical motor circuitries. Neurosci. 2007;147 (1):224-35

88. Sen S, Kawaguchi A, Truong Y, Lewis MM, Huang X. Dynamic changes in cerebello-thalamo-cortical motor circuitry during progression of Parkinson's disease. Neurosci. 2010;166(2): $712-19$.

89. Yu H, Sternad D, Corcos DM, Vaillancourt DE. Role of hyperactive cerebellum and motor cortex in Parkinson's disease. Neuroimage. 2007 Mar;35(1):222-33.

90. Palmer S, Ng B, Abugharbieh R, Eigenraam L, McKeown MJ. Motor reserve and novel area recruitment: amplitude and spatial characteristics of compensation in Parkinson's disease. Eur J Neurosci. 2009;29:2187-96.

91. Stern Y. Cognitive reserve. Neuropsychologia. 2009 Aug;47(10): 2015-28.

92. Friston KJ. Commentary and opinion: II. Statistical parametric mapping: ontology and current issues. J Cereb Blood Flow Metab. 1995;15(3):361-70.

93. Palmer SJ. Compensatory Mechanisms in Parkinson's Disease. PhD thesis: Vancouver: University of British Columbia; 2010.

94. Kwak Y, Peltier S, Bohnen NI, Müller ML, Dayalu P, Seidler RD. Altered resting state cortico-striatal connectivity in mild to moderate stage Parkinson's disease. Front Syst Neurosci. 2010 Sep 15;4:143.

95. Palmer SJ, Li J, Wang ZJ, McKeown MJ. Joint amplitude and connectivity compensatory mechanisms in Parkinson's disease. Neurosci. 2010;166(4):1110-18.

96. Stevenson J, Oishi MMK, Farajian S, Cretu E, Ty E, McKeown MJ. Response to sensory uncertainty in Parkinson's disease: a marker of cerebellar dysfunction? Eur J Neurosci. 2010;33(2):298-305

97. Baddeley RJ, Ingram HA, Miall RC. System identification applied to a visuomotor task: near-optimal human performance in a noisy changing task. J Neurosci. 2003;23(7):3066.

98. Kording KP, Wolpert DM. Bayesian integration in sensorimotor learning. Nature. 2004:427(6971):244-7.

99. Vaziri S, Diedrichsen J, Shadmehr R. Why does the brain predict sensory consequences of oculomotor commands? Optimal integration of the predicted and the actual sensory feedback. J Neurosci. 2006;26(16):4188-97.

100 . Wei K, Stevenson IH, Kording KP. The uncertainty associated with visual flow fields and their influence on postural sway: Weber's law suffices to explain the nonlinearity of vection. J Vis. 2010;10 (14):4.

101. Wolpert DM, Ghahramani Z. Computational principles of movement neuroscience. Nat Neurosci. 2000 Nov;3 Suppl: 1212-17.

102. van Beers RJ, Baraduc P, Wolpert DM. Role of uncertainty in sensorimotor control. Philos T Roy Soc B. 2002;357(1424): 1137-45. 